\title{
Narrar la ambivalencia desde el cuerpo: diálogo sobre nuestras propias experiencias en torno a la "no-maternidad"
}

\author{
Claudia ANZORENA \\ Sabrina YÁÑEZ \\ claudia_anzorena@yahoo.com.ar
}

Recibido: 01.03.2013

Aceptado: 09.11.2013

\begin{abstract}
RESUMEN
En este artículo compartimos un diálogo en torno a nuestros procesos personales de decidir sobre la propia maternidad, la articulación entre maternidad institucionalizada y heteronormatividad, y las posibilidades de elegir no tener hijos/as. Nuestras resistencias al mandato de la maternidad heteropatriarcal, como así también nuestras ambivalencias en el proceso de decisión, son formas de transgresión y rebeldía que se materializan en nuestros cuerpos. Creemos relevante recuperar nuestras vivencias como feministas de los años '90 y 2000 porque a través de la politización y la reflexión de la propia experiencia anclada al cuerpo, a la clase, la etnia y la cultura nos constituirnos en sujetos políticos colectivos y construimos teoría desde la que pensarnos y pensar la sociedad sexualmente marcada, por lo cual nuestros testimonios aportan a los procesos de construcción de las decisiones personales, de las luchas políticas y de los sujetos de los feminismos.
\end{abstract}

Palabras clave: No-maternidad, Experiencia, Cuerpos, Feminismos, Heteropatriarcado.

\section{Narrating embodied ambivalence: a dialogue about our "non-motherhood" experiences}

\begin{abstract}
In this article, we share a dialogue about our personal decision-making processes regarding motherhood, the convergence of institutionalized motherhood and compulsory heterosexuality, and the possibility of actively choosing non-motherhood. We claim that our resistances to the mandate of hetero-patriarchal motherhood -as well as the ambivalences present in our decision-making processes- are forms of embodied transgression and rebellion. We find it relevant to rescue our testimonies as feminists living in the decades of 1990 and 2000 because we believe that by rendering political our own experiences anchored in our bodies, our social class, ethnic origin and cultural inheritance, we become part of a political collective and we build theory that serves as a ground to think about ourselves and about our gendered society. Thus, our testimonies contribute to the processes of making personal decisions, sustaining political struggles and defining the subjects of feminisms.
\end{abstract}

Key words: Non-Motherhood, Experience, Bodies, Feminisms, Heteropatriarc 
“¿Para cuándo los hijos?” es una pregunta con la que frecuentemente, palabras más o menos, y con mayor o menor presión, nos encontramos las "hembras" humanas adultas sin hijos/as. La aparente inevitabilidad de esta pregunta, para quienes no somos madres (independientemente de si queremos o no serlo), nos incitó a emprender la tarea de compartir algunas reflexiones que nos hemos hecho de manera conjunta, en torno a cómo es no ser madre en una sociedad heteropatriarcal, donde la maternidad es destino y definición de lo femenino.

Si las sociedades capitalistas y patriarcales (entendidas como el conjunto de instituciones y de relaciones sociales complejas que las constituyen) definen a las mujeres como madres heterosexuales que cuidan niños y niñas heterosexuales, necesariamente nuestras resistencias al mandato atraviesan las relaciones con nuestros propios cuerpos y nos dejan en un lugar limitado para nombrarnos como mujeres que deciden de manera libre no tener hijos/as, sin hacer referencia a la carencia ( $\sin$ hijos/as), a la biología (nulíparas, estériles) o a la negación del mandato o la institución (no-madres o no-maternidad). Utilizaremos el concepto "no-maternidad" para hacer referencia a las mujeres que en edad reproductivas no tienen hijos/as, por elección o no, a sabiendas que es un concepto discutible y cargado de ideología, pero lo marcamos como un punto de partida para ubicarnos en los debates sobre la maternidad como mandato, como definición de lo femenino y como institución.

Nosotras, compartimos diferentes espacios: de militancia, académico y laboral, de recreación y amistad. En varias ocasiones, hablando de nuestros temas de investigación y de nuestras experiencias personales y colectivas, llegábamos a un asunto recurrente: las presiones sociales sobre tener hijos/as. Ante esto, el lesbofeminismo y el feminismo, como campos de acción y de reflexión, nos permitieron sostener nuestra resistencia al mandato de la maternidad institucionalizada; pero mientras para una había dado lugar a la posibilidad de un proyecto de maternidad diferente, para la otra había habilitado la posibilidad de no ser madre.

Nuestro objetivo es recuperar dos genealogías que consideramos muy enriquecedoras para los feminismos: una es la revalorización de la experiencia como fundamento de la práctica y la teoría feminista, y la otra la consideración de no tener hijos/as biológicos o adoptados/as como un proyecto de vida posible y legítimo.

En este artículo compartimos nuestros testimonios en forma de diálogo en torno a los procesos personales de decidir sobre la propia no-maternidad, la articulación entre maternidad y heteronormatividad, y las posibilidades de elegir no ser madres ${ }^{1}$.

\footnotetext{
${ }^{1}$ La forma de diálogo de este trabajo está inspirada en un artículo de Gayle Letherby y Catherine Williams (1999).
} 
Nuestras resistencias al mandato de la maternidad heteropatriarcal son formas de transgresión y rebeldía que se materializan en nuestros cuerpos, tal como plasmamos en los relatos que presentamos. Creemos que es necesario ubicar la elección de no gestar ni parir como una opción real en el movimiento y la teoría feminista, como una condición necesaria para la existencia de una maternidad voluntaria y plena. Del mismo modo que sin derecho al aborto no hay derecho a la maternidad voluntaria, tampoco lo hay sin derecho a la "no-maternidad" como elección y no como destino trágico.

La relevancia de recuperar nuestras vivencias como feministas de 2000 se basa en que seguimos sosteniendo que la politización de la propia experiencia anclada al cuerpo, la clase, la etnia y la cultura nos permite constituirnos como sujetxs políticxs colectivxs, por lo cual nuestros testimonios y los de otras mujeres en torno a la nomaternidad aportan a los procesos de construcción de las decisiones personales, de las luchas políticas y de lxs sujetxs de los feminismos (Ciriza y otras/os, 2010).

En cuanto a la intención de partir desde nuestros testimonios, no lo hacemos para ubicarnos en un lugar irrefutable, sino que, en el sentido que plantea Dorothy Smith, nos proponemos tomar el punto de vista de las mujeres, no como una forma de conocimiento dada y finalizada (y por tanto indiscutible), sino como una manera de asentarnos en la experiencia -en este caso la propia- para hacer descubrimientos a partir de ella. Somos conscientes del predominio de una conciencia bifurcada que genera una relación jerárquica entre formas de conocimiento científico $\mathrm{y}$ de conocimiento cotidiano. En este sentido, tomamos de la autora la propuesta de formular una sociología que comience en lo concreto de la vida cotidiana y que ancle la investigación de lo social en las actividades y decisiones diarias. Comenzar por la experiencia es lo aprendido en el movimiento de mujeres, y Smith decidió llevarlo también a su concepción y práctica sociológicas (Smith, 2005: 8, 32). En sus escritos explica que la presencia de las mujeres generó problemas para el mundo académico que aspiraba a la neutralidad y la objetividad:

"Lo que ha sido repugnante, peligroso para la pureza del mundo del intelecto iluminado, es la presencia del cuerpo mortal que la presencia de las mujeres inserta, nuestra ruptura con la división que permite a la mente no reconocer que tiene un cuerpo, que habita en él y que no es separable de él" (Smith, 2005: 23).

\section{EL LUGAR DE LA "NO-MATERNIDAD" COMO REIVINDICACIÓN FEMINISTA.}

La institución de la maternidad es una construcción cultural que impone a las mujeres formas monolíticas de vivir y de entender sus propios cuerpos sexuados 
(Yañez, 2009). Adrienne Rich efectuó la primera distinción detallada entre maternidad como institución y maternidad como experiencia, explicando cómo la institución de la maternidad ha alienado a las mujeres, encerrándolas en sus propios cuerpos. Así se ha asegurado el control de los cuerpos de las mujeres, en cuanto a reproducción pero también en cuanto a la sexualidad, por parte del patriarcado, adaptando sus configuraciones a las necesidades económicas y políticas de los sectores hegemónicos a lo largo de distintos momentos históricos. En palabras de Rich "cualquier institución que llega a expresarse tan universalmente [como la de la maternidad] termina por afectar profundamente nuestra experiencia, incluido el lenguaje que usamos para describirla" (1986:42). Es por esto que emprendimos la tarea de rastrear y analizar algunos textos y artículos feministas sobre la decisión de no ser madres.

En el campo de la teoría feminista se viene desarrollando una gran variedad de aportes críticos en torno al tema de la maternidad como institución y sobre cómo, en las sociedades capitalistas y patriarcales, se define a las mujeres como madres heterosexuales que cuidan niños y niñas heterosexuales (Tarducci, 2008). Las construcciones de la feminidad y los roles sociales asignados a las mujeres han sido histórica y tradicionalmente armados sobre prácticas y simbolismos alrededor de la maternidad (Fernández, 1994). La maternidad se percibe así como natural para las mujeres, como un deseo inevitable, incuestionable y central en la construcción de una "feminidad normal". Entonces, las mujeres adultas que deciden no ser madres son frecuentemente vistas y tratadas como anormales, y la "no-maternidad" voluntaria es percibida como egoísmo y una desviación aberrante, antinatural y antifemenina, a tal punto que ni siquiera existe un término que nombre de manera afirmativa a las mujeres que no son madres por voluntad. Por otra parte, a las mujeres que no tienen hijos/as por algún motivo físico se las cataloga de "infértiles", son estigmatizadas como cuerpos que fallan, se las considera enfermas que deben someterse a la medicalización (Gillespie, 2000) ${ }^{2}$. Ya en los '70, Adrienne Rich llamaba la atención sobre esto. La escritora planteaba cómo a lo largo de su libro tuvo que recurrir a términos como "sin hijos" (childless) o "libre de hijos" (childfree), porque no encontraba ningún nombre para designar a las mujeres que se identifican consigo mismas y se definen por elección apartadas de las relaciones con hijos/as. Muchos conceptos definen a las mujeres en términos de carencia, de rechazo a la maternidad, o bien están plagados por prejuicios de promiscuidad sexual o relacionados con la castidad. La "mujer sin hijos" vs. la "madre", dice Rich, son falsas polarizaciones que sólo benefician a la institución de la maternidad y a la heterosexualidad obligatoria (Rich, 1986[1976]: cap. IX-9).

\footnotetext{
${ }^{2}$ Entre los testimonios que encontramos de mujeres no-madres aparecía también la situación de las no-madres involuntarias, es decir, mujeres que desearon ser madres pero no lo fueron por impedimentos físicos pero tampoco se sometieron a tratamientos médicos ni quisieron adoptar.
} 
Ann Snitow hace un recorrido por las representaciones y las propuestas del feminismo en torno a la maternidad y la "no-maternidad" desde la década de los "60 (Snitow, 2004: 48). La autora señala que una de las reivindicaciones más radicales de los movimientos feministas de los países occidentales industrializados de los '60 y '70, fue la posibilidad para las mujeres de plantearse proyectos de vida por fuera de la maternidad. Esta posibilidad era producto de la crítica a la maternidad como destino único y obligatorio y de la familia nuclear hetero-patriarcal como lugar de concentración de la subordinación y dominación de las mujeres.

En los años '80, las perspectivas políticas dominantes de la Nueva Derecha volvieron a la carga con la ideología de la maternidad: ensalzaron los valores familiares tradicionales asociados con parentesco, los roles sociales "naturales" y la contención del comportamiento sexual en la familia nuclear (Gillespie, 2000). Ante la necesidad de enfrentarse a posturas cada vez más conservadoras, muchas de las reivindicaciones más radicales se evaporaron, entre ellas la posibilidad de elegir una vida plena sin maternidad para las mujeres. Snitow asevera que:

“...ya pasó mucho tiempo desde que las feministas que demandaban el aborto pusieran en el centro la idea de que uno de los buenos usos que se le puede dar a este derecho es el de no tener hijos en absoluto. Corregidas en los años reaganianos, las estrategias a favor de la legalidad del aborto comprensiblemente han destacado el derecho a esperar, el derecho a espaciar los nacimientos, el derecho a tener sólo hijos(as) deseadas(os). Temieron involucrar alguna imagen que pudiera ser leída como una retirada femenina del rol nutricio. Estamos -en este periodo de reacción- elaborando, extendiendo, reinstitucionalizando la maternidad para nosotras mismas" (Snitow, 2004: 48).

Otras autoras coinciden con el planteo de Snitow en cuanto a la pérdida de la celebración de la resistencia del mandato de la maternidad en las voces más escuchadas del feminismo actual. Carolyn Morell comenta cómo el feminismo occidental en las décadas del ' 80 y del ' 90 ha reflejado el mismo "renacimiento maternal" de la cultura dominante (Morell, 2004[1992]). Por su parte, para Gayle Letherby y Catherine Williams el feminismo ha simplificado el asunto como una elección más de las mujeres, sin contemplar qué implica esta decisión, quién tiene posibilidad de elegir y en qué condiciones (Letherby \& Williams, 1999) ${ }^{3}$.

Para Rosemary Gillespie el feminismo, aunque ha promovido la elección y los derechos reproductivos, ha fallado en la incorporación de las experiencias de no-

\footnotetext{
${ }^{3}$ En este sentido para las autoras las mujeres que por razones físicas no pueden engendrar, no tienen posibilidad de elegir si ser madres o no. En nuestro contexto, siendo el aborto ilegal, la posibilidad e imposibilidad de elegir está directamente relacionada con los recursos económicos y simbólicos de las mujeres, determinados por la clase, la edad, el color de piel, etc. Esto no es incompatible con la posición de las autoras ya que sin condiciones económicas tampoco es posible acceder a las tecnologías de reproducción.
} 
maternidad voluntaria en la teoría y en la praxis, como proyecto legítimo (Gillespie, 2000). Maxine Molyneux señala que durante los años ' 80 y ' 90 , en algunos países latinoamericanos muchas activistas feministas esgrimieron argumentos "familistas", que buscaban conjugar igualdad y protección, porque lo consideraban el modo más adecuado de lograr consenso para impulsar la reforma de los derechos legales (Molyneux, 2003: 266s). En el foro mexicano Ni Madres, varias de las participantes cuentan que no han sentido su decisión como válida para cierto feminismo y para los movimientos de izquierda (Foro Ni Madres, 2004).

Snitow va más allá en cuanto agrega que la "reinstitucionalización" de la maternidad se evidencia en obras que intentan paliar visiones anteriores que excluían las experiencias de las "otras" mujeres (pobres, lesbianas, negras, indígenas, etc), pero que terminan elogiando a las mujeres que crían a sus hijos/as solas o en la pobreza, o frecuentemente en ambas circunstancias (Snitow, 2004). Esto contribuye, a su vez, a otorgarle más legitimidad a las políticas sociales que sólo apuntan a darles algunos recursos a las mujeres para que sigan cargando sobre sus espaldas todo el peso de las tareas de cuidado y crianza (Anzorena, 2009).

Lo interesante de estos planteos -que invitan a pensar la no-maternidad como una posibilidad- es que nos proponen, como feministas, el desafío de abandonar el único "privilegio" exclusivo que ostentan las mujeres -la maternidad- a cambio de algo que todavía no podemos concebir.

\section{UN PROCESO AMBIVALENTE: PUNTOS DE PARTIDA}

Sabrina: Desde pequeña el tema de la maternidad me traumatizaba. Vengo de una familia de clase media, numerosa, y soy la mayor de cinco hermanos/as. Recuerdo algunas escenas puntuales de mi infancia en nuestra casa de barrio. En esos tiempos (los ' 80 y principios de los '90) mi mamá trataba de combinar nuestra crianza primero con sus estudios terciarios y luego con su trabajo como docente de primaria. Durante la semana mi papá trabajaba en el taller de electricidad del automóvil de su padre y pasábamos la mayor parte del tiempo con mamá, con las abuelas o en la escuela. Mis dos hermanos se peleaban con frecuencia y mi hermana menor era muy inquieta. La otra se pasaba limpiando, según ella, para no tener que escuchar a mi mamá quejarse tanto. Y yo, a mis 10 u 11 años, me empeñaba en abstraerme del caos y mantener un mínimo espacio propio para estudiar y soñar despierta. Era una época de convicciones en cuanto a ciertas cosas: quería ser escritora, tener un caballo y no quería nunca, pero nunca, ser madre. Mi mamá ha de guardar varios papeles con mis declaraciones firmadas que dicen: "nunca tendré hijos". Aunque la admiraba, no podía comprender cómo podía preferir dedicar tanto tiempo y paciencia a seres tan "ingratos" y "demandantes", en vez de centrarse en proyectos propios, individuales, 
tales como viajar y ser famosa por algún arte. Por supuesto, el epíteto de egoísta no tardaba en aparecer para calificar mi temprano rechazo de la norma.

Recuerdo también que me espantaba lo que oía y leía sobre los dolores del parto. De niña tenía mucho miedo al dolor físico. Tuve la suerte de pasar una infancia bastante sana y poco accidentada. Mi cuerpo era para mí, en ese momento, un lugar de secretos placeres (aunque culposos).

Con el paso del tiempo mis convicciones fueron mutando. Nunca tuve el caballo, mis poemas y cuentos no pasaron a mayores, y en cambio me volqué a las ciencias sociales. En cuanto al proyecto de no-maternidad, la adolescencia me encontró con una culpa exacerbada por sentirme individualista y atormentada por el descubrimiento de mi deseo lesbiano. Deseé no tener cuerpo, ser "leve y pura". Comía poco, hacía ejercicio compulsivamente y casi me atrapó la anorexia. Pensé también que tener una "familia propia" haría que desaparecieran las culpas, y así cumpliría con el ideal de "niña buena" y dedicada a los/as demás que la religión católica había logrado imprimir en mí a pesar de mis resistencias. Me crucé con un par de varones dispuestos a "ayudarme" a concretar ese plan, pero siempre primó la duda y una suerte de pánico ante el prospecto de una vida heterosexual monogámica, familiar y rutinaria. Recuerdo que el temor al embarazo fue una constante en mis relaciones sexuales con varones, a pesar de haber mediado siempre el preservativo.

Claudia: Tengo 34 años, soy heterosexual y no soy madre porque no he querido. La no-maternidad ha sido un proceso ambivalente en mi vida: a veces una forma activa de resistencia a los mandatos sociales, que obligan a las mujeres a ser madres independientemente de si lo desean o no, otras simplemente no me dieron ganas o estaba ocupada en diferentes cosas.

Nací en la ciudad de Mendoza. Provengo de una familia de clase media profesional, mi mamá es profesora y licenciada en historia y mi papá es ingeniero. El mandato primordial fue estudiar y la educación pública y gratuita un valor a defender.

Recuerdo claramente cuando comencé a cuestionarme la posibilidad de tener hijos/as, tenía 19 años. Hasta entonces lo veía como algo que iba a pasar en algún momento, como un camino natural, pero me preocupaba en desmedida que fuera antes del momento "adecuado". El aborto ya era para mí una salida aceptable, aunque no tenía la menor idea de cómo acceder en caso de que fuese necesario. Tuve un "susto" en el último año de la escuela secundaria y de ahí en más la anticoncepción se me hizo carne, sobre todo ante la angustia y la soledad que pasamos cuando somos adolescentes y sentimos que no tenemos a quién recurrir, que el sexo es tan irresistible como malo, y que el castigo va a llegar. 
Cuando descubrí que gran parte de lo que se me permitía y se me prohibía se debía al hecho de ser mujer, empecé un camino sin marcha atrás de cuestionamiento. Estaba en la facultad y estudiaba sociología, carrera que me sentaba muy bien por "mi actitud" (y esto no era un cumplido). En el camino de la lucha de clases, el superhombre de Nietzsche y Las palabras y las cosas de Foucault, conocí al feminismo: un colchón de argumentos, de reconocimiento y de "hermanas" en el cual te podías dejar "caer", y todo un mundo por transformar. El feminismo setentista y "anacrónico" -como me decían algunas compañeras-que encontré en la biblioteca de la Facultad puso palabras y acción a mi inconformidad. "Escupir sobre Hegel", como me proponía una tal Carla Lonzi, era lo más irreverente que podía existir, más que las marchas y las tomas en contra de la reforma universitaria de los ' 90 . Y conocí otras mujeres que tenían las mismas intenciones... y al affidamento y al continuum aunque a los conceptos mucho después. Conocí las formas de la opresión: el matrimonio, la maternidad, la heterosexualidad, el patriarcado, la familia burguesa, el orgasmo vaginal subsidiario al placer del varón y atado a la reproducción, la pobreza con "rostro" de mujer, la desigualdad de las relaciones de género. Conocí las formas de la lucha: la resistencia a los mandatos, los encuentros de mujeres, y sobre todo que el aborto era un derecho a decidir sobre mi cuerpo que era mío, que nadie podía interferir en mi vida... como yo ya sospechaba. Además, sin dios ya no había castigo divino que me alcanzara.

En síntesis, más o menos al mismo tiempo, "dios murió" y yo no tendría hijos/as. Fue un descubrirme capaz de resistir a los mandatos sociales, de ser como esas mujeres fuertes y autónomas que tanto admiraba. Y de orgullosa que me sentía de mi decisión tampoco escatimé en hacerla de público conocimiento. Me acuerdo cuando lo dije delante de mi "novio" de ese entonces. Había otras personas amigas, y mis justificativos no alcanzaron para que no fuera tildada de egoísta. No tener hijos/as era egoísta. A mí me parecía más bien todo lo contrario. Igual no me tomaron muy en serio. Era muy joven y a esa edad aparentemente es común pensar así, ya tendría tiempo para cambiar de opinión, seguramente cuando madurase y/o encontrara al hombre indicado. Estas respuestas desvalorizantes -egoísmo, inmadurez, inestabilidad emocional- que suenan casi-casi como una maldición, me han seguido por años. Con el tiempo aprendí a moderar el discurso y saber qué decir en qué ámbito. La tan mentada madurez me hizo más cauta que otra cosa.

\section{CONOCER A LA PERSONA "INDICADA", TAREA TRABAJOSA SI LAS HAY...}

Sabrina: La posibilidad de estudiar y vivir en otros países me habilitó una mirada más amplia y compleja sobre las relaciones de parentesco y la posibilidad de una vida por fuera de la heteronormatividad. Obtuve una beca para hacer mi carrera de grado 
en Canadá, una licenciatura combinada en antropología y sociología. Allí, donde el movimiento LGTTBI ha logrado muchos avances, pude concebir la idea de vivir una relación lesbiana sin tantos miedos, sin tanta sensación de estar decepcionando a todo el mundo -especialmente a mi familia. Participé de varias actividades de la comunidad lesbiana, como la primera marcha lésbica de Vancouver, ciclos de cine y shows de drag kings. En mi último año de universidad cursé una materia llamada "Políticas de la Familia" y leí varios artículos sobre maternidad lesbiana. Escribí mi ensayo final sobre el potencial de las familias encabezadas por lesbianas para romper con los roles tradicionales de crianza y establecer relaciones de pareja más democráticas en cuanto a la división del trabajo doméstico y del cuidado.

Cuando terminé la carrera, volví a Argentina con ganas de trabajar para el cambio social. Una amiga y una profesora de posgrado -Alejandra Ciriza- me mostraron el camino del feminismo en Mendoza. Aunque tenía lecturas feministas y una noción aguerrida con respecto a mi autonomía, fue mi primera experiencia en el movimiento. La teoría feminista lesbiana, en particular, me permitió creer en la posibilidad de vivir la maternidad de manera más plena y compartida. Por primera vez pude considerar a la maternidad como parte de un proyecto de vida y no como su némesis.

Al poco tiempo de regresar al país formé una relación estable con una mujer y le planteé mi deseo de tener un/a hijo/a juntas. En principio, ella aceptó y celebró esta idea. Fue el momento de mayor convicción con respecto al deseo de ser madre, a pesar de que la idea conllevaba bastantes ambivalencias con respecto a cómo concebir (primaba la idea de recurrir a un amigo gay, porque los bancos de esperma estaban fuera de nuestras posibilidades económicas), a cómo nos organizaríamos para la crianza (si involucraríamos o no al padre biológico y cómo haríamos para romper la dicotomía madre gestante/madre no gestante), y a la tristeza de no poder generar un ser a partir de nosotras dos. Además, nos preocupaba el desamparo a nivel legal que tendrían ella como madre no biológica y nuestro/a hijo/a. Pero aún así el proyecto de maternidad se me presentaba como lleno de oportunidades de aprendizaje, lucha y transformación. Mientras tanto, mi familia asumía que si yo estaba en una relación con una mujer no iba a tener hijos/as, y de vez en cuando expresaban su tristeza porque yo no iba a "formar una familia propia".

Pasado un tiempo, mi relación de pareja se fue desgastando y el proyecto de maternidad compartida se fue haciendo menos factible, hasta que la relación concluyó. Desde entonces, me he preguntado mucho sobre mi visión -tal vez idealizada- de las maternidades lesbianas como "automáticamente" radicales. Las maternidades lesbianas me parecen radicales en cuanto existen tensiones en la intersección entre la institución de la maternidad y la de la heterosexualidad 
obligatoria: rompen con el imperativo mujer=madre=heterosexual ${ }^{4}$, ampliando los significados y las prácticas de la maternidad por fuera de las nociones heteropatriarcales. Por otro lado, no creo que las madres lesbianas escapen necesariamente de los mandatos de "crianza apropiada". Tal vez las parejas de mujeres pueden evadirse en cierta medida de la división sexual del trabajo, pero se requiere de mucha conciencia y diálogo para sostener prácticas disidentes en cuanto a la crianza. Como integrante de una colectiva feminista lesbiana, tengo la oportunidad de seguir pensando estos temas en espacios colectivos y acompañar a mis compañeras de militancia tanto en sus proyectos de maternidad como de no-maternidad.

Claudia: En relación a mis parejas, más de uno se transfiguró cuando dije que yo no iba a tener hijos/as y se decepcionó ante mi negativa de ser "la madre de sus hijos/as", lo que en ocasiones derivó en rupturas... que dolieron. Una vez, cuando me enteré que uno de ellos iba a tener un hijo, alguien me comentó: "podrías haber sido vos". Eso nunca lo entendí. Yo no "habría sido", porque como dije la anticoncepción para mí era carne. Un determinismo absurdo: como si ciertos espermatozoides tuvieran marcado en su destino el fecundar, le toque a quien le toque.

Cuando conocí a H. que, sin que yo dijera nada, me comentó que nunca iba a tener hijos/as, simplemente me flechó: iba a ser mi compañero de toda la vida. Pero no. Ahora está casado como la ley y dios mandan, y es padre. También me dijeron que podía haber sido yo, pero el espermatozoide predestinado tampoco me tocó. En un momento de esta relación -tenía 27 años- me cansé de sentirme esclava de las pastillas, de la biología, del destino de la especie, y comencé una cruzada para colocarme un DIU. Ahí tuve una categoría en la que encajaba: yo era una "nulípara", y para las "nulíparas" no se recomienda el uso del DIU, porque algunas de sus complicaciones pueden producir esterilidad, y eso no es tolerable en una mujer que no tiene hijos/as; además, según la OMS somos más promiscuas. Yo pregunté si las "nulíparas" teníamos más riesgo de complicaciones que las mujeres con partos, y la respuesta fue que no, pero si quedaba estéril no los/as iba a poder tener. Le dije a la ginecóloga que yo no quería tener hijos/as, y me dijo que ya iba a cambiar de opinión. Una vez que me planté en que estaba dispuesta a correr el riesgo, me recomendó comenzar a tomar ácido fólico para prevenir las malformaciones fetales (i?). No podía salir de mi asombro: todo lo que yo decía era tomado como pasajero. Al final lo logré, desvalorizada en mi decisión, infantilizada, conseguí que se respetara mi decisión.

En ese momento de mi vida, la anticoncepción me daba la suficiente seguridad como para no tener que ser tan sincera con relación a la maternidad. Por otro lado, la

\footnotetext{
${ }^{4}$ Aunque con la ley de matrimonio igualitario, ya no necesariamente con el imperativo mujer $=$ madre $=$ esposa.
} 
lucha por la legalización del aborto me permitió conocer distintas formas de acceder a una interrupción del embarazo si fuese necesario. Adquirí un conveniente discurso de que el deseo de un hijo o una hija tenía que ser el producto del amor de dos personas. Que yo no quería tener hijos/as en ese momento o en cualquier situación, pero que si el anhelo surgía a partir del amor, del compartir, de construir proyectos, que sería posible. Muchas veces traté de fantasear y sentirme cómoda en esta idea, de creerme lo que decía, que podría ser más fácil conservar una pareja o darle otro sentido a mi vida. Inclusive elegí un nombre: se llamaría Faustina, que significa "feliz, a quien favorece la suerte". Pero también fantaseé con quedar estéril, con algo verdaderamente dramático que inhibiera a las personas de volver a preguntar o de hacer comentarios.

\section{EL MOMENTO ACTUAL: PENSANDO DESDE NUESTROS CUERPOS}

Sabrina: Mi actual pareja es un varón sensible y reflexivo con el que comparto muchos proyectos: escribimos juntxs, viajamos en una bicicleta tándem, tenemos una pequeña huerta. Desde el principio he manifestado mis dudas sobre asumir la maternidad; él las respeta y, en general, las comparte. En este momento, en el que tengo la posibilidad de la reproducción biológica con mi pareja (al menos hasta que se demuestre lo contrario), no tengo una decisión tomada que sea definitiva. Predomina la ambivalencia. Puedo imaginarme una vida plena tanto con hijxs como sin hijxs. El haber podido concebir como posible el "no", me habilita un "ś́" más genuino.

A decir verdad, me tienta la idea del embarazo, el parto, la lactancia. Vengo de un recorrido de redescubrimiento de los potenciales de mi cuerpo. El año pasado, mi compañero y yo cruzamos la cordillera de los Andes en nuestra bicicleta tándem. Fue un viaje hermoso, lleno de oportunidades de conectar con nuestros cuerpos, de explorar sus límites y sus posibilidades, sus goces y sus cansancios extremos, además de lo simbólico de haber compartido el esfuerzo. Considero a los procesos físicos de la maternidad como avenidas de acceso a un mayor conocimiento y disfrute de mi cuerpo, como ha propuesto Adrienne Rich en Nacemos de Mujer. Para que eso sea posible, sin embargo, quisiera transitar estos procesos por fuera de las imposiciones del sistema de salud que considera a las mujeres embarazadas como enfermas y ejerce prácticas invasivas en el momento del parto. Me aterra pensar en convertirme en un cuerpo arrojado a la vulnerabilidad, para que otrxs intervengan en él y decidan qué es mejor (siempre en función de el/la bebé) sin consultarme ni respetar mis decisiones. Me espanta la idea de la maternidad biológica como una entrega de mi cuerpo que se escape de mi control.

De todos modos, tampoco puedo concebir al cuerpo como algo meramente "natural". Si algo he aprendido del feminismo es que ni siquiera lo físico es 
meramente biológico, ni deslindado de mandatos. En estos procesos entran en juego factores históricos, sociales, culturales, políticos, económicos. Entonces, no hay experiencia personal "impoluta" posible del cuerpo. Mi forma de relacionarme con mi cuerpo carga con influencias familiares, religiosas, culturales (como los imperativos estéticos, como toda la literatura que he absorbido, entre otras cosas)... Si he de transitar el camino biológico de la maternidad, tendrá que ser con mucha conciencia y gran tolerancia a la ambivalencia, algo para lo cual no somos preparadas.

Claudia: El embarazo me da impresión. No puedo "concebir" la transformación y el hecho de que otro ser habite mi cuerpo. Y después nacen: ¿y la pérdida de la libertad? A mí personalmente los/as bebés no me emocionan. Muchas veces en mi vida me pareció más atractivo el lugar asignado a los varones: perseguir un proyecto, una carrera, trascender por algo diferente a los/as hijos/as. Los mandatos no pesan sobre ellos como sobre nosotras.

En el momento en que cruzás los 30 años, las personas se ponen más insistentes. Logré muchas de las cosas que quería y que me hacen sentir orgullo de mí misma, he sido bastante coherente, soy inquieta y luchadora, y soy feliz casi todo el tiempo; igualmente me llené de canas y engordé varios kilos, pero nada de eso produce la misma aprobación que "un hijo". Conocí, de una manera bastante accidentada, a un varón que comparte mi decisión de no tener hijos/as, y con quien queremos estar y vivimos juntos/as. Sin embargo, esto produce más desconcierto aún. Ahora, inclusive mujeres feministas y con conciencia de género, que daba por sentado que entendían la no-maternidad como un proyecto posible, me han dicho cosas como "yo quiero que tengas un hijo" o me preguntan "cuándo", o me dicen "yo pensé que ahora ibas a tener un hijo".

Además se respira maternidad por todas partes. Mis amigas comenzaron a tener hijos/as, otras en este momento están tan convencidas que buscan formas de realizar su deseo con o sin pareja. Yo por mi parte sigo buscando razones para justificar mi negativa. Siento que mi cuerpo ya no está para un embarazo y que no tengo ganas de estar a mis 50 años preocupada por adolescentes. Que los/as hijos/as en todo caso los/as tendría que haber tenido de joven, pero claro, estaba muy ocupada tomando conciencia. Siento que ya no es tiempo para mí, y esto inclusive me da alivio. No sé si tanto como el que, intuyo, me dará la nunca bien ponderada menopausia.

\section{EL MUNDO Y NUESTRAS DECISIONES, O NUESTRAS DECISIONES EN EL MUNDO}

Sabrina: En cuanto a la crianza, considero que hay un potencial de hacerla diferente, compartida y no normativa. Pero nada me asegura el éxito en esta sociedad, 
que nos seguirá ubicando a mi compañero y a mí en los lugares heteronormativos que rechazamos y que exigirá a mis hijos/as que se ubiquen en determinados roles. Sería un compromiso continuo al interior de la pareja y una lucha continua hacia el exterior. Por otro lado, siento que es difícil no reproducir el modelo de la familia nuclear monogámica, responsable exclusiva por la crianza. La colectivización es tentadora, en teoría. Tengo una familia extendida que espera ansiosa mis hijos/as y que promete ayudar en su crianza, pero siento que replicarían muchos estereotipos de género y sexualidad. Aún así, no me parece justo negarles a mis hijos/as las bondades del parentesco biológico.

Me asusta también cómo se juegan las expectativas propias sobre los/as hijos/as. No podemos imponerles nuestros sueños, sería contradecir nuestra lucha por la libertad y la autonomía. Tendríamos que aceptar lo impredecible como parte del proyecto.

Claudia: Cada vez que veo este mundo se me parte el corazón. La pobreza. La tristeza. La muerte. Las enfermedades. La discriminación. La marginación. La incertidumbre. La desprotección. Vuelvo a sentir alivio de no ser responsable del sufrimiento de los hijos y las hijas que no tuve. Y ya no reconozco en mí, si la ambivalencia se dirime entre maternidad sí/maternidad no, o entre cuáles de mis razones son más contundentes. Simplemente diría no porque no. Ojalá no tuviera que justificar mi decisión. En ese caso quizá me dejaría relajar en mi resistencia. Quizá dejaría a la especie manifestarse en mí... o no. Pero en este mundo tal cual es, sería darle la razón al presagio de que todas, tarde o temprano, caemos en el mandato.

El miedo a la soledad, a la vejez y a la muerte no me problematizan. Quizá porque todavía me siento lejos de eso. Sí me inquieta un poco más la sensación de que este mundo necesita más de gente diferente que lo haga un mejor lugar. Sin embargo, si bien estoy segura que nosotras, las "diferentes" por lesbiana y/o feminista, podemos soñar con criar niños y niñas distintos/as, creo que son expectativas que no tengo derecho a poner sobre otros/as aunque fueran mis hijos o hijas. A veces, lo que temo es la posibilidad del arrepentimiento, de llegar al momento en que no haya opción, y que la profecía se cumpla. Supongo que ahí tendré que lidiar con mis propias supersticiones, y hacer el duelo de lo que nunca quise y pude haber querido.

\section{HABLAR DE/DESDE NUESTRAS PROPIAS EXPERIENCIAS}

Sabrina: Desde que comencé a investigar sobre las tensiones entre la maternidad como institución y como experiencia, me he propuesto construir la memoria de mi experiencia en relación con la maternidad a pesar de que (¿todavía?) no tengo hijos/as. El asunto de la maternidad atraviesa, como mujer, mi cotidianeidad, y como 
antropóloga, mis indagaciones académicas; aunque podría decir que también allí donde se hace político lo personal - en la militancia feminista lesbiana- la maternidad permea mi lucha. Es una doble lucha: por un lado, contra la maternidad obligatoria y por otro, a favor de la maternidad libremente elegida y vivenciada.

Este ejercicio de escribir sobre la propia experiencia para explorar su inserción en procesos políticos y colectivos más amplios ha sido complejo pero necesario. Complejo porque la experiencia se me ha presentado siempre como contradictoria y casi inasible, y necesario porque al poner el cuerpo a los temas que militamos y que estudiamos nos reconocemos como parte de un colectivo (y no sólo analistas o portadoras de estandartes) y encarnamos este momento histórico. Al dialogar con Claudia y con otras mujeres no madres, he encontrado en nuestras experiencias semejanzas que reafirman mis razones y mis luchas. También he encontrado diferencias que han ampliado mi perspectiva, habilitándome otras miradas sobre lo que significa habitar este mundo en cuerpos de mujeres y permitiéndome ver la riqueza de posibilidades que tanta falta hace ante los significados monolíticos que impone el patriarcado con sus instituciones.

Claudia: Este ejercicio de hablar/escribir sobre nuestras experiencias personales en torno a la no-maternidad me ha resultado difícil, movilizador. Me comprometió a repensar y poner en palabras cuestiones que una prefiere no discutir, volver inmune a los comentarios, al mandato: no ser madre por voluntad, en una sociedad que permanentemente te marca como incompleta, requiere valor como señala Morell (2004[1992]: 40), sobre todo cuando cruzás los 30, sos heterosexual y estás en pareja.

Sin embargo, la dificultad no estuvo dada sólo por cómo abordar el tema, sino también por cuál era el sentido de hablar de mi propia experiencia. En cierto modo hacía tiempo que estaba alejada de los relatos que me tocan y encarno. Hace unos 10 años que analizo las relaciones sociales desde espacios de producción y reproducción de la ideología y las prácticas patriarcales dominantes, que se ensañan especialmente con mujeres definidas como madres, pobres, desempleadas, subocupadas, vulneradas; mujeres que penden del gobierno como clientas de políticas sociales. En estos análisis descubrí más de una vez que yo "no existo" como mujer desde el punto de vista de la responsabilidad del Estado: no soy madre, no soy pobre, no soy oscura, no soy migrante, no soy huérfana o pertenezco a una familia "desamblada", no soy víctima de violencia, no he sido violada, no soy analfabeta ni analfabeta funcional, y además no carezco de la información y los recursos para acceder a anticonceptivos y abortos seguros. La lista es larga y me ubica en un lugar de "privilegio" frente a otras, otros y otrxs. El Estado se desentiende de mí como mujer, para él yo no necesito nada porque me las rebusco por "mis" medios. Soy invisible en cuanto no me adecuo a los modelos de elegibilidad. A menudo me siento disconforme en los mandatos y estereotipos que nos asignan a las mujeres, hasta el punto de sentirme incómoda en mi 
cuerpo y en las formas que otras asumen el "ser mujer" acríticamente. Pero también muchas veces me he relajado en mi cómoda condición y me he quedado, podríamos decir, tranquila en cómo defiendo los derechos de "las demás". He construido mi grupo de pertenencia de militancias y de afectos, y tengo una familia que me quiere y me permite ser como soy. No necesito, al menos conscientemente, dar permanente batalla contra las discriminaciones que nos atraviesan.

De este modo se me presentaba como indecente, egoísta o inadecuado hablar de mi propia experiencia. La urgencia de las condiciones materiales de opresión y discriminación en que viven tantas otras y otrxs hace complicado pensar cuánto me debe este mezquino sistema hetero-sexista-patriarcal-capitalista-conservador como ciudadana, como clienta y como empleada del Estado o simplemente como sujeta, como amiga, como compañera, como hija, como NO madre.

Fue de gran valor y ayuda para mí leer sobre la importancia de la experiencia, encontrarme con los relatos de otras que, como yo, eligieron y siguen eligiendo no ser madres, y redescubrir que lo personal aunque no sea "trágico" puede ser siempre político y un camino para reflexionar sobre nuestras vidas.

Por otra parte a mis casi 35 años me produce tedio, cansancio, aburrimiento explicar por qué NO, sobre todo dado que parece una necesidad (casi una obligación) de los y las demás, el expresar su desconcierto en torno a "los hijos" que no tengo y que muy probablemente no tendré. Es así que ya no recuerdo si mi arsenal de razones me hicieron llegar a la conclusión de que no quiero tener hijas/os, o si fue rehusarme a la maternidad lo que me obligó a construir un arsenal de razones para justificar y legitimar mi decisión. Una determinación que en sí misma no es tan contundente o invariable o eterna, sino que la resistencia al mandato, las presiones externas, llevan a no poder/deber hacer hincapié en la ambivalencia de la decisión. Decisión tan ambivalente como cualquier otra, con la diferencia de que si nuestra cultura desalienta la opción voluntaria por la no-maternidad de las mujeres, es implacable y dilapidaria en la condena de las mujeres que tienen hijos/as y se dan cuenta que no los quieren o que no pueden ser madres ${ }^{5}$.

Resulta difícil expresar estos sentimientos sin sentir que estoy hiriendo o atacando a otras que eligieron ser o son madres, muchas de ellas mujeres que amo profundamente. Lo mío, claro, no es nada personal con ellas. Como indica Morell, muchos de los mensajes que promueven la maternidad no pretenden que las mujeres

\footnotetext{
5 Esta situación me recuerda a la película "Las Horas" donde el personaje que encarna Juliane Moore, al final explica por qué se fue y dejó a su hijo e hija: "Sería... maravilloso decir que te arrepientes. Sería fácil. Pero, ¿qué significa? ¿Qué significa arrepentirse cuando no se tienen alternativas? Es lo que puedes tolerar. Así fue todo. Nadie me perdonará. Era la muerte. Elegí vivir.”
} 
sin hijos/as se sientan mal, sino que las que sí los tienen se sientan bien (Morrell, 2004[1992]: 40). Las formas en que el mandato de la maternidad se construye llevan al falso dilema de que ser madre y no ser madre son opuestos e irreconciliables.

Finalmente, creo que un asunto de tal envergadura merece un tratamiento que dé crédito a un tema tan desvalido: el resistir a la maternidad para quienes no podemos verla por fuera del mandato impuesto o simplemente no es un proyecto deseado. Pido disculpas si no estuve a la altura de la tarea, pero haciendo mías las palabras de Audre Lorde: “...hablar me resulta provechoso más allá de cualquier efecto” (Lorde, 2007: 12).

\section{CONSIDERACIONES FINALES}

"Qué queremos unas de otras/ después de haber contado nuestras historias/ Queremos/ ser curadas queremos/ una musgosa calma que crezca sobre nuestras cicatrices/ queremos/ la hermana todopoderosa que no asuste/ que hará que el dolor se vaya/ que el pasado no sea así" (Audre Lorde) ${ }^{6}$.

Como sugiere la cita de Lorde, nos resultó importante preguntarnos ¿qué queremos al narrar nuestras experiencias como mujeres cientistas sociales y feministas del sur que en este momento no tenemos hijos/as? ¿Qué queremos, parafraseando a Rich, al nombrarnos en los intersticios del lenguaje donde descansan los poderosos secretos de la cultura? Queremos la comprensión y contención de la hermandad que reconozca nuestra elección y condición como válidas, y también queremos pensarnos como colectivo que se construye, se desarma y se reconstruye a partir de la experiencia común compartida y de la discusión de cuestiones que son excluidas de las voces dominantes.

Entonces ¿qué queremos al buscar una forma de nombrarnos y relatarnos por fuera del mandato por excelencia? Desafiar las ideologías, desafiar nuestras propias prácticas que deifican también algunas ideologías, mostrar nuestra inconformidad con los discursos que nos describen y nos indican nuestras "desviaciones", confrontarlos, problematizarlos, incomodarlos.

En cuanto nos entendemos y nos sentimos parte del campo amplio, fértil y heterogéneo de análisis y de prácticas políticas que son los feminismos, tenemos la responsabilidad de plantear nuestras perspectivas de manera constructiva, para reconocernos como participantes y no como observadoras externas y juezas de las demás. Es tratar de encontrarnos, de apropiarnos de lo que el feminismo tiene de

\footnotetext{
${ }^{6}$ Audre Lorde, "No Hay Poemas Honestos sobre Mujeres Muertas” citado por Rich (1986).
} 
promesa, de alegría, de potencial de hacernos más dichosas (flores, 2010), de nombrarnos desde un lugar que afirme nuestra elección.

En indagaciones conjuntas, venimos explorando diferentes dimensiones de la experiencia y su relación con el cuerpo, enfocándonos principalmente en las experiencias de (lo que llamamos provisoriamente) "no-maternidad", no como contracara de la maternidad sino como inserta en el corolario de la institución de la maternidad. En este sentido, avanzamos en la revalorización de nuestras experiencias como fundamento de la práctica y la teoría feministas y en plantear la opción de no tener hijos/as como una elección posible y legítima para las mujeres.

Por otra parte, para explorar las configuraciones de las representaciones sociales de la no-maternidad en el ámbito local, llevamos a cabo un taller de reflexión con 11 mujeres que no son madres, de distintas edades, orientaciones sexuales y posicionamientos respectos de su posibilidad de maternidad. Las reflexiones surgidas en el taller dan cuenta de la "incomodidad social" que provocan las mujeres sin hijos/as, que se expresa en una serie de representaciones contradictorias. Se las descalifica en su capacidad de cuidado y en sus opiniones sobre la crianza, pero a su vez se las considera siempre disponibles para cuidar a otros/as. Se les tiene compasión pero también se envidia su libertad. Se afirma la inevitabilidad de su destino de madres, pero sólo en caso de ser heterosexuales. Las contradicciones que se expresan en los estereotipos y los comentarios dirigidos hacia las mujeres que no son madres generan malestares y constantes replanteos sobre las decisiones tomadas o sobre las propias trayectorias.

Existe en nuestra cultura una prohibición que impide plantear la ambivalencia como parte de las cuestiones de maternidad (y por extensión, de no-maternidad) (Rich, 1986[1976]). Una madre debe amar incondicionalmente. Una mujer debe tender naturalmente -sin lugar a las dudas- hacia la maternidad. Esto produce sensaciones de inadecuación tanto a las madres como a las no-madres. Retomando la idea de Rich y de Smith (entre otras) de escribir teoría feminista desde la propia experiencia y la de otras mujeres, los testimonios propios y los recogidos no se presentan como simples anécdotas, sino como ejemplos encarnados de cómo las mujeres criticamos los mandatos pero a la vez construimos nuestras decisiones y nuestras vidas en constante negociación con ellos. A pesar de los avances en derechos sexuales y reproductivos, sigue siendo un desafío para las mujeres generar identidades por fuera del mandato biológico de la maternidad y su forma institucionalizada. Las mujeres que no desean tener hijos/as, por las razones que sea, muchas veces se encuentran defendiendo sus decisiones en soledad, como si se tratara de posiciones irracionales y extremistas. Las formas en que el mandato de la maternidad se construye lleva al falso dilema de que ser madre o no ser madre son opuestos e irreconciliables. Sin embargo, las decisiones, nada acabadas, ambivalentes, 
de no-maternidad no tienen que ver con ser o no ser madres sino con un rechazo a la maternidad institucionalizada, con negarse a ser madres bajo cualquier circunstancia o a ser "sólo madres", esto muy unido a la afirmación de lo vocacional y de "otros proyectos". Si planeamos la maternidad, lo hacemos no como objetivo de vida sino como una forma más de experiencia y expresión de las posibilidades de la vida. En este sentido nuestros testimonios muestran la ruptura de las dicotomías a través de los relatos de experiencias, habilitando los matices, mostrando que en la vida las decisiones no se plasman en un negro o blanco, sino que existen grises donde las mujeres transitamos nuestras decisiones.

\section{BIBLIOGRAFÍA}

ANZORENA, C. (2009): Veinte años de políticas públicas destinadas a mujeres en la argentina. Organismos y políticas en la provincia de Mendoza. Buenos Aires, Tesis doctoral FCS - UBA (Inédita).

CIRIZA, A. y otras/os (2010): Experiencia política, memoria, género. Perspectivas críticas desde la filosofía y las ciencias sociales. Mendoza, Proyecto de Investigación Plurianual No313 2010-2012 CONICET.

FERNÁNDEZ, A. (1994): La mujer de la Ilusión. Buenos Aires, Paidós.

FLORES, V. (2010):"Desorganizar el cuerpo hetero: prácticas de saber/coger como experiencia política". CD Actas de las X Jornadas Nacionales de Historia de las Mujeres y V Congreso Iberoamericano de Estudios de Género, Luján, UNLuján.

FORO NI MADRES (2004): Debate Feminista, Año 15, Vol. 29, p. 3-39.

GILLESPIE, R. (2000): "When No Means No: Disbelief, Disregard and Deviance as Discourses of Voluntary Childlessness". Women's Studies International Forum, Vol. 23, $\mathrm{N}^{\mathrm{o}} 2$, p. 223-234.

LETHERBY, G. y WILliAMS, C. (1999): "Non-Motherhood: Ambivalent Autobiographies". Feminist Studies, Vol. 25, No 3, p. 719-728.

LORDE, A. (2008) Diarios del Cáncer. Rosario, Hipólita Ediciones.

MOLYNEUX, M (2003): Movimiento de mujeres en América Latina. Estudio teórico comparado. Valencia, Cátedra-Feminismos.

MORELL, C (2004): "Necesitar y encontrar el valor" Debate Feminista, Año 15, Vol. 29, p. 40-46.

RICH A. (1986[1976]): Of Woman Born. Motherhood as Experience and Institution, Nueva York, WW Norton.

SMITH, D. (2005): Institutional Ethnography. A Sociology for People, Toronto, Altamira Press.

SNITOW, A (2004[1992]): "Maternidad: la recuperación de los textos demoníacos". Debate Feminista, Año 15, Vol. 29, p. 47-56.

TARDUCCI, M. (2008): "Presentación" en: Tarducci, M. (org.) Maternidades en el siglo XXI; Buenos Aires: Espacio. 
YAÑEZ, Sabrina (2009): Tensiones entre la maternidad como institución y la maternidad como experiencia. Una exploración desde la etnografía institucional y de lo particular en el interior de la Argentina en el periodo 2001-2010. Proyecto de Tesis de Doctorado, FFyL - UBA. 